\title{
Adolescent School-Based Sexual Health Education and Training: A Literature Review on Teaching and Learning Strategies
}

\author{
Hussein Haruna ${ }^{1}$, Xiao $\mathrm{Hu}^{1} \&$ Samuel Kai Wah $\mathrm{Chu}^{1}$ \\ ${ }^{1}$ Division of Information and Technology Studies, Faculty of Education, The University of Hong Kong, Hong \\ Kong \\ Correspondence: Hussein Haruna, Division of Information and Technology Studies, Faculty of Education, The \\ University of Hong Kong, Hong Kong. E-mail: hharuna@hku.hk
}

Received: January 15, 2018 Accepted: February 8, 2018 Online Published: February 19, 2018

doi:10.5539/gjhs.v10n3p172 URL: https://doi.org/10.5539/gjhs.v10n3p172

\begin{abstract}
Objectives: The objective of this review is to gain an understanding of the teaching approaches used and their effectiveness in imparting sexual health literacy amongst school adolescents. The intention is to design interventions for effective sexual health education in our study setting.

Methods: We reviewed various literature related to adolescent sexual health education studies that have been conducted by prior researchers. We also provide an overview of the teaching and learning methods used.

Results: Through this literature review, we learned that GBL and gamification were carried out primarily in developed countries, outside of Africa. It has been observed that both GBL and Gamification are effective and efficient in the transformation of knowledge, as they influence students' learning processes through engagement, enjoyment, excitement, attractiveness, and participation. They also foster critical thinking skills, improve confidence, increase motivation, and stimulate a habit of self-regulatory learning among students.
\end{abstract}

Conclusions: Ensuring the impartation of sexual health knowledge can also be achieved by designing and applying effective innovation teaching methods that appeal to today's youth, such as GBL and Gamification. We will design GBL and Gamification methods and evaluate their effectiveness amongst Africans students, specifically among Tanzanian school adolescents.

Keywords: sexual health, school adolescents, sexual health literacy, sexual health education, literature review

\section{Introduction}

Adolescence, or puberty, is a period of great opportunity and hope. It is the period between childhood and adulthood when young people undergo physical, mental, and emotional changes. This period can be confusing for some adolescents because most become sexually active without having the knowledge required to manage their sexual behaviour (Mlyakado, 2013b), due to biological factors caused by hormone changes (Walcott, Meyers, \& Landau, 2008). When a growing person enters puberty (adolescence) he or she becomes interested in sex, but is emotionally immature and frequently ignorant. While others manage to make the transition to adulthood without getting involved in risky sexual behaviours, others fail to overcome the challenges of this critical stage and eventually miss the opportunity to realize their full potential in life. The main reason is that most of them are sexual health illiterate.

Adolescents who fail to manage their biological changes are driven by emotions that are associated with the increase of hormones during adolescence. Most of them are susceptible to risky sexual behaviours, such as underage sexual intercourse, having sexual intercourse with many partners, and participating in unprotected sexual activities (Mlyakado, 2013a). These adversely affect their future health outcomes through such things as increasing their chances of getting sexually transmitted infections (STIs) including HIV/AIDS, and becoming school dropouts because of pregnancy (Walcott et al., 2008). One of the most significant commitments a country can make to its economic, social, and political progress, and to its stability, is to invest in the growth and development needs of its adolescents, which includes educating them about sexual health.

Sexual health education programmes in many countries aim to impart adolescents with the information they need to make informed decisions related to sexual issues during adolescence (Mueller, Gavin, \& Kulkarni, 2008). Sexual health education is improving and is reducing cases associated with irresponsible sexual behaviour within 
the adolescent age group. Adolescents who are sexual health illiterate are more likely to participate in underage sexual intercourse, unsafe sex, and sexual assault (Che, 2005; Peter, 2013; Shegesha, 2015). Cervical cancer, unplanned pregnancies, and dropping out of school (Eggers et al., 2016; Mathews et al., 2012; Sommer, Likindikoki, \& Kaaya, 2015; Kirby, 2002; K. Mkumbo et al., 2009; Smith \& Harrison, 2013; Speizer et al., 2003) are more common among those who have underage sexual intercourse. These adverse effects may not only affect their childhood but could also prove detrimental to their adult life-socially, culturally and economically (Shemsanga, 2013; Ubora wa Afya kwa Familia Duniani, 2001).

Sexual health education teaches adolescents how to make right decisions about their sexual behaviour and improve their health status (Buston, Wight, Hart, \& Scott, 2002; Daniel Wight, Plummer, \& Ross, 2012). These initiatives have been jointly implemented by international and local organisations. Various national and international movements support adolescents' rights to sexual health-related information. In order to determine the most effective approach to establishing sexual health literacy, we conducted a literature review pertinent to the adolescent sexual health education approaches currently being used globally, and in Africa and Tanzania respectively. The results of this literature review analysis will inform researchers and designers involved in sexual and reproductive health education the best and most effective innovations in teaching methods which can appeal to school adolescents.

\section{Adolescent Sexual Health Education}

\subsection{Global}

Risky sexual behaviour amongst adolescents owing to a lack of sexual education has become a global concern. Sexual health education initiatives have been integrated into secondary school curricula in many countries throughout the world to educate young people on how to make informed choices, and to increase awareness of the consequences of risky sexual behaviour.

Thus, adolescents need to be provided with a comprehensive package programme for effectively transforming their sexual knowledge. Just teaching them abstinence alone or giving them no sex education knowledge may make them more prone to unexpected teenage pregnancy or to being infected with STIs (Kohler, Manhart, \& Lafferty, 2008) due to practicing unprotected sex, having limited access to contraceptive facilities and services, and engaging in unsafe abortions after having unwanted pregnancies. Hence, when providing sexual educational programmes, sensitive issues like confidentiality, privacy, compassion, and individual rights as young adolescents should be taken into consideration (Shaw, 2009), which may facilitate the development of sexual education programmes that better suit their requirements and ensure effective knowledge transformation. The most successful and comprehensive sexual education programme is grounded on an established educational theory supporting voluntary thinking, emotional and behavioural change (Ponzetti, 2016).

The significance of sexual education among the younger generations is widely acknowledged. Mellanby, Newcombe, Rees, \& Tripp (2001), for instance, stress health and education organisations working jointly to develop strategies for supporting sexual education among young generations both at home and in schools. To date, various strategies have been employed: many countries have integrated sexual education programmes within school curricula for students aged 12 to 16 (Chu et al., 2015; Mellanby et al., 2001), and in some instances parents or guardians have been encouraged to educate their children on these matters while at home (Wight \& Fullerton, 2012).

Even if all initiatives taken so far advocate sex education among school teenagers, this approach seems to be ineffective and has ultimately proven to fail (Che, 2005). Reasons put forth for this failure include: 1 . Current sex education programmes in schools are limited by scant government emphasis, 2. Restricted time and space, 3 . Inadequate teaching and learning materials, 4. Ineffective traditional teaching methods, 5. Lack of policy, 6. Insufficient skilled expertise (Hong Kong Department of Health, 2014), and 7. Taboos against socio-cultural values like speaking about sex in public in some countries (Okazaki, 2002).

\subsection{Africa}

Before the HIV/AIDS pandemic in Africa, sexual health education for adolescents consisted of discussions that were private due to social and cultural reasons. At the time, the focus was to impart knowledge so as to protect them from STIs such as syphilis and gonorrhoea. Also, they were taught how to behave during adolescence. Adult males would talk with adolescent boys and adult females did the same with the girls (Shemsanga, 2013). In schools, teachers would teach them about the mammal reproductive system, whereby topics such as the human reproductive system and sexual health behaviour were taught in the classroom, but with great care and respect for sensitive cultural issues. 
The number of adolescents with HIV/AIDs, STIs, underage pregnancies, rape experiences, and those who have dropped out of school has been increasing (Tiendrebéogo, Meijer, \& Engleberg, 2003). The statistics provided by (UNAIDS, 2016; WHO, 2016) indicate that in Sub-Saharan African (SSA) the issues related to HIV/AIDS are very serious. For example, recent data from 2015 indicate that globally there are 36.7 million people living with HIV/AIDS, of which 2.5 million are new infections. UNAIDS and WHO further report that the most affected area is Sub-Saharan Africa, with approximately 25.6 million people living with HIV/AIDS, accounting for two-thirds of the world's total. More specifically, there were about 1.8 million adolescents under 15 living with HIV/AIDS globally in 2015, of which 1.6 million are from Sub-Saharan Africa. Furthermore, globally, there are about 150,000 adolescents under 15 years old who were newly infected with HIV/AIDS in 2015, 120,000 of which are from Sub-Saharan Africa. About 110,000 adolescents under 15 years old are dying of AIDS globally, of which 91,000 are from Sub-Saharan Africa. In addition, the report showed that the four countries with the highest rates of infected adolescents aged 10 to 19 years in Sub-Saharan Africa are South Africa, Nigeria, Kenya, and Tanzania.

This situation calls for African governments, in collaboration with various international and local development partners, to develop ways to curb this situation. UNESCO (2013) stipulated that such initiatives as sexual education programmes be developed, during the International Conference on Population and Development (ICPD) in 1994, and in the Transparent and Participatory Accountability Strategies for Monitoring and Implementing Sexual Education Programmes. Other initiatives include the 45th Session of the Declaration on Youth and Adolescents for Sexual Education (The Commission on Population and Development, 2012), the 2003 Maseru Declaration for Combating HIV/AIDS, and the African Commission held in Maputo in 2006, during which sexual education among adolescents was also taken into consideration.

The initiative most widely adopted in Africa is the inclusion of sexual education in primary and secondary schools. East and Southern African (ESA) countries have jointly developed a sexual health education curriculum. The goal was to increase adolescent knowledge regarding protective behaviours, including rejecting unwanted sex, delaying involvement in sexual intercourse, and practicing safe sex (Population Council, 2012). Sexual education in ESA countries covers: (a) self-awareness, self and others' relationships and power in relationships; (b) human development, puberty, the body, and reproduction; (c) sexuality and sexual behaviour (d) sexual health: STIs/HIV/AIDS/STDs, and their prevention using condoms, treatment, care; (e) sexual health: such as pregnancy, contraception, and abortion; and (f) communication, negotiation, and decision-making skills. Delivery of this sex education programme to students in ESA countries mainly uses the traditional teaching methods.

Despite the remarkable efforts made so far through many years of investment in developing these programmes, their implementation has several limitations: (a) There exist misconceptions regarding the concept of sex education, which is still vague and sometimes mysterious to most implementers; (b) Sexual education is not a stand-alone programme, but rather is included within other subjects; (c) Teachers have limited ability to use participatory teaching methods; and (d) Teachers lack a background in health education and reproductive health knowledge (Tiendrebéogo et al., 2003). African governments rely heavily on international development organizations for initiatives and money (F. Okonofua, 2014). There is little initiative by or support from local African governments, and there is an acute shortage of people trained in sexual health education. Consequently, the implementation of sexual education programmes in most African countries is insufficient.

Cultural factors also limit the teaching of sexual education in schools. Those who teach are often challenged by colleagues and community members for contradicting African norms, morals, and beliefs (Hsu, 2010). In addition, a lack of systematic training, limited support from relevant authority, limited content and resources, little time allocated, and traditional methods of teaching have also been noted among other factors contributing to ineffective sexual health education programmes for adolescent African students (Ahmed, Flisher, Mathews, Mukoma, \& Jansen, 2009; Arnab et al., 2013). Naidoo (2006), for instance, after conducting a qualitative study which intended to examine the effectiveness of sexual education programmes in schools in South Africa, discovered that students were more interested in other exciting interactive teaching methods than only lecturing.

\subsection{Tanzania}

The United Republic of Tanzania is the largest country in East Africa, covering 940,000 square kilometres, 60,000 of which are inland water ways (The United Republic of Tanzania, 2013). In Tanzania, young people aged 10 to 24 years old constitute $32 \%$ of the population. A third are these are adolescents (10 to 19 years old) (National Adolescent Reproductive Health Strategy 2011-2015). Their large numbers make it inevitable that programmes would be developed to address adolescent health and development. For this reason, Tanzania, apart from being a signatory to various international and regional conventions that promote adolescent sexual and reproductive health, has developed policy documents in which young people's needs are addressed. These were all products of 
collaboration between stakeholders drawn from various government departments, civil society, and multilateral agencies.

From an education point of view, the Ministry of Health (in collaboration with the Ministry of Education and Vocational Training) promotes sexual health education through the National School Health Programme. Through this latter programme, young people are provided with a number of health care services that provide information on their sexual and reproductive health, as well as counselling support. The Ministry of Education and Vocational Training has also brought HIV education into national school curriculum.

Despite these initiatives, there are still obstacles to adolescents accessing quality sexual and reproductive health information and services. This accounts for the fact that adolescent pregnancy is still a major challenge in this country. For instance, two-thirds of women in Tanzania are married before their 20th birthday, and about a quarter (23\%) of girls aged 15 to 19 in Tanzania have already begun childbearing. This reflects their limited access to sexual and reproductive health information, among other things (2004-2005 Tanzania Demographic and Health Survey). Adolescent pregnancies have a major negative effect on the education of young girls in Tanzania, not to mention complications arising from early childbearing, unsafe abortions, and the spread of HIV and other STIs. Such problems are exacerbated by the existence of socio-cultural factors such as gender norms, encouragement of early and forced marriage, and female genital mutilation (FGM) (United Republic of Tanzania, Ministry of Health and Social Welfare, Reproductive and Child Health Section, 2011).

Adolescent sexual activity is a real threat to Tanzania. The majority of adolescents engaged in sexual activity below 15 years of age have little knowledge on sexual health issues, and less than half of adolescents have even adequate knowledge about sexual health (AVERT, 2016). For instance, $9.7 \%$ of adolescent girls and $10.2 \%$ of boys had experienced sexual intercourse before age 18 (The United Republic of Tanzania, 2013). Every year, almost 130,000 people are infected with HIV/AIDS and STDs due to sexual activity (MoEVT, 2014). Moreover, it is noted that Tanzania has the highest rate of adolescent pregnancy in the world (Makoye, 2015). According to Makoye, approximately 8,000 unwanted pregnancies occur among adolescent women in Tanzania, and account for one in six students attending school. Some scholars (Sommer et al., 2015) suggest that imparting knowledge of responsible sexual behaviour among adolescents should be done before puberty, or else it will then be difficult to change adolescent behaviour through later sexual education. This is why, according to Bilinga (2016) and Klepp, Flisher, \& Kaaya (2008), most secondary school students in Tanzania have limited understanding of (1) healthy sexual behaviour, (2) contraception, and (3) reproductive health.

In partnership with others, in 2015 the Tanzanian government launched various sexual health education programmes that have aimed to curb the negative effects of underage sex (Makoye, 2015). Such initiatives target boys and girls who had never been taught anything about sex before. These initiatives in Tanzania include establishing sex education clubs in schools; providing sexual health education training to school teachers, and integrating sexual education into curricula (M. Bilinga \& Mabula, 2014; Makoye, 2015; Mkumbo, 2009; Shegesha, 2015).

In consequence, sexual education programmes now are widely integrated into school curricula in Tanzania. However, sex education in Tanzania is mostly covered within the subjects of social studies, civics, science, and biology (Mkumbo, 2009). It is not detached from the other subjects. Sexual education sub-topics include 1. Family issues; 2. The human body and cleanliness; 3. HIV/AIDS, STIs, and STDs; 4. Life skills; 5. Dating and marriage; 6. The rights and responsibilities of family members; 7. Proper behaviour and good manners; 8 . Decision making; 9. Gender issues; 10 . Customs; 11 . Diseases and infections; 12 . Family planning; 13 . Sexuality, sexual health, and good manners; 14. Sexual behaviour; and 15. Maternal and child care. In addition, they were taught adolescence, adolescent reproductive development, contraception, abortion, human sexuality, gender, love and relationships, violence, STIs, HIV/AIDS, and life skills (Ubora wa Afya kwa Familia Duniani, 2001).A large number of sexuality-related curricula for adolescents have been developed in Tanzania by the government and both local and international-stakeholders.

\section{Overview of Teaching and Learning Approaches in Sexual Health Education}

\subsection{Traditional Teaching Method}

The traditional teaching method holds that the teacher has the power and responsibility for constructing the lectures and making the decisions regarding the content and specific outcomes. In other words, "the traditional method gives teachers the impression that they cause learning to occur" (Jack, 2015, p. 8). In that teaching approach, teachers believe that the student's head is empty and needs to be filled with information. The teacher has the power over students' knowledge transfer through preparation, teaching, and assessment. The main strength of 
the traditional teaching approach is that it has some potential merits regarding the development of student IQ and EQ (Liu \& Long, 2014, p. 8). It is commonly held limitation is that it inhibits and controls students' ability to express their own thoughts.

The traditional teaching approach has been used for centuries. However, due to the development of technology, is has been more recently regarded as ineffective for imparting knowledge today. Schwerdt \& Wuppermann (2011, p. 1) argues that the traditional teaching approach has been characterised by three major issues. First, it suffers from constraints in providing feedback to instructors about their learners, and assumes that all students can learn at the same pace. Second, learners are not active listeners under traditional teaching. Third, gives the impression that learners can only learn by listening.

Despite its weaknesses, the traditional teaching method is still widely used in many developing countries where technology is limited. Akkus, Gunel, \& Hand (2007, p. 1749) contends that the traditional approach holds teachers to be the only knowledge transmitters, whereas students are just receivers of the knowledge imparted by their instructors. As highlighted by Akkus et al. such means of perceiving the process of knowledge transmission disempowers students and authorizes only teachers to influence the nature of classroom interaction, including the initiation of questions and the exchange of thoughts among students.

Within sexual health education, reasons that teachers tend to employ the lecture method include the avoidance of too many questions from the students, fewer potential complications compared to participatory teaching methods, greater levels of attention payed by the students, frequent lack of confidence in the topic due to socio-cultural issues, lack of skills related to the subject, lack of teaching facilities for doing demonstrations, and large numbers of students in the class which makes it difficult for teachers to handle if they were to apply other teaching approaches.

\subsection{Game-Based Learning}

Before defining GBL, it is important to understand the term 'Game'. According to Kapp, (2012 p. 7), a 'game' is an interactive activity in which certain players, who are supposed to adhere to certain rules and guidelines take part in order to achieve certain results or outcomes. Thus, when people are engaged in games which are purposefully designed to achieve a certain outcome, it could be said that they are directly or indirectly able to learn something which is meaningful and not just for entertainment (Blunt, 2006). As such, GBL is effective and efficient at transferring knowledge, as it influences students' learning process through engagement, enjoyment, excitement, attractiveness, and participation (Admiraal, Huizenga, Akkerman, \& Dam, 2011). GBL fosters critical thinking skills and improves confidence in students (Cicchino, 2013). GBL has been reported to motivate students (Harrold, 2015) and to stimulate a habit of self-regulatory learning among students (Xu, 2012). GBL offers attractive and unlimited opportunities to students to learn at their own pace.

Other effectiveness characteristics of GBL have been identified by numerous scholars. For example, according to Blunt (2006), GBL is an effective learning tool for facilitating students to apply, practice, and develop higher order thinking skills and gain understanding more quickly than with traditional teaching. Nevertheless, Perry (2016) argues that the most efficient GBL should be designed in a way that supports students' participation by integrating player capabilities with relevant game features and course content. This can enable easy implementation on the part of stakeholders because the games are acceptable, usable, and employed by students to acquire a certain field of knowledge (Chu et al., 2015).

A high-quality serious game with all the required features and navigability can attract students to play it, with knowledge gain being a resulting by-product. For example, any game encourages students to compete for higher scores than opponents. Contrary to traditional methods of teaching, the GBL process is considered most likely to be more fun and comforting during teaching and learning (Xu, 2012). Learners in this current century require learning approaches which enable them to learn in a way which can motivate and encourage their learning. Teaching methods that bore learners can never be given high priority in this era in which technology seems so attractive and promising. Learners are interested in collective and competitive reasoning in the sense that it can enable them to focus on their learning objective while competing for higher scores (Jimenez-gomez, 2015).

\subsection{Gamification}

There is a connection between game-based learning and gamification, as both involve game mechanics. Gamification is "using game-based mechanics, aesthetics, and game thinking to engage people, motivate action, promote learning, and solve problems" (Karl M. Kapp, 2012, pp. 9-10). Gamification is a wider concept which can be divided into two main areas, structural gamification and content gamification:

- Structural gamification "is the application of game elements to propel a learner through content with no 
alteration or changes to the content." In the educational context, this kind of gamification can be implemented by adopting score elements, such as point scoring, badges, leaderboards, and achievements (K. M. Kapp, Blair, \& Mesch, 2013, p. 224).

- Content Gamification "is the application of game elements, game mechanics, and game thinking to alter content to make it more game-like" (Kapp et al. (2013: 237). Through this kind of gamification certain game elements, such as a storyline, characters and mystery, are added to learning content in order to engage students.

Gamification emerged from the business field, where "game mechanics techniques" from video games were applied to non-game situations with the purpose of increased engagement and motivation, and the encouragement of particular learner behaviours (Simõesa, Redondob, \& Vilasb, 2013). According to Hanus \& Fox (2015), gamification evolved from advertising. However, it originally arose, its potential was recognized after it was applied to health and education. Within education, gamification is still a relatively new idea.

A previous systematic mapping study (Dicheva, Dichev, Agre, \& Angelova, 2015) divided game elements into two parts, mechanics and design principles.

\subsubsection{Game Mechanics}

According to Dicheva et al. (2015) game mechanics consists of point systems, badges, levels, a leaderboard, virtual goods, and avatars. Bunchball Inc. (2010) asserts that the mechanism employed to gamify a task or an activity is known as game mechanics. The following are commonly known and used game mechanics: (i) points, (ii) levels, (iii) trophies, (iv) badges, (v) achievements, (vi) virtual goods, (vii) leader boards, and (viii) virtual gifts.

\subsubsection{Design Principles}

Design principles consists of a goal or challenge, personalization, rapid feedback, visible status, unlockable content, freedom of choice, freedom to fail, a storyline or new identities, onboarding, time restriction, and social engagement.

\subsubsection{Game Dynamics}

Game-dynamics are the needs, aspirations and motivations geared toward engaging the player's emotions. These include: (a) rewards, (b) status, achievement, (c) self-expression, (d) competition, and (e) altruism. Also, according to Hanus and Fox (2015), gamification can be applied using different forms of learning, such as: 1. The application of narratives to amend the setting of a typical task; 2. The design of social competition; and 3. Provision of incentives like rewards and badges in order to motivate behavioural change. This approach encourages engagement and participation in learning for the purpose of gaining knowledge for behavioural change among individuals. In education transformation, some researchers (Behnke, 2015; Landers \& Callan, 2011) address the potential of gamification in increasing student engagement and fun. In their opinion, through gamification students can be encouraged to transform their knowledge by playing a game in order to perform academic activities while enjoying playing the game in question.

Hence, since gamification has already been employed in education (Filsecker \& Hickey, 2014; Garcia et al., 2014), it may also be used in adolescent sexual education. This could be an effective way to promote and impart knowledge about sexuality among secondary school adolescents, encouraging them to abstain from engaging or participating in various irresponsible behaviours. This has been acknowledged by other scholars (Hew, Huang, Chu, \& Chiu, 2016) who view game mechanics as an innovative teaching tool which is effective in motivating, engaging, interacting and amusing young adolescents during learning.

\section{The Role of GBL in Adolescent Sexual Health Education}

GBL is among the most technologically innovative ways of promoting sexual health education, and seems to be promising and attractive to the present generation. Delivering sexual education through GBL is more likely to be harmless, comforting and supportive in cultures where talking about sex in public is taboo (Okazaki, 2002). This teaching and learning technique may promote skill transformation, such as problem solving and collaboration, which can be emphasized through GBL to promote sexual education among adolescents.

GBL sometimes called Serious Games (SG) are games whose main purpose is something more serious than just entertainment. One such serious purpose is education. Such games transform learners' lives while they are having fun (McGonigal, 2011). According to (Arnab \& Clarke, 2015), GBL can foster cognitive knowledge, create awareness, and facilitate behavioural change. Research has been conducted to develop games that have these effects in sexual health education. For example, a study conducted by Arnab et al. (2013) involving a 
multi-disciplinary team of researchers from the UK, created SG for adolescent relationships and sexual education. The GBL developed was tested using a cluster randomized controlled trial. A total of 505 students aged between 13 and 14 from local schools were invited to participate in the study. The GBL approach was reported as having positive learning outcomes. Authors suggested blending interactive GBL with traditional learning to motivate discussions among teachers and students within their communities.

Their study (Arnab et al., 2013) came up with an evaluation and analysis approach which focused on one part of the game, gameplay, rather than the full game activity, as being capable of augmenting sexual education. Perhaps this should be considered one of the major limitations of this study. In addition, although this research attests to the effectiveness of GBL in promoting sexual education among adolescents, it does not point out ways to address any challenge encountered during implementation. Furthermore, the research does not specify which technological tool was used to play the game. This missing information could help other researchers repeat a similar study.

A study by Bowen et al. (2014) developed GBL for adolescents to raise awareness of and encourage behavioural change related to dating violence. The scholars used focus group interviews to collect data from thirteen adolescents aged between nine and ten. They also used a thematic analysis technique to analyse the data. The results proved that GBL is a positive pedagogy in terms of instructional principles and for delivering training content. Bowen and colleagues reported technical problems associated with GBL, particularly in relation to functionality, such as technological shortages and insufficient participant instructions. The technical problems pointed out are really important for other researchers to take into consideration in their studies. The number of participants involved in the study was limited, which makes the findings questionable. In order to make the obtained findings more valid, a large number of respondents should be involved. Furthermore, just one research approach was employed rather than enriching their findings by applying a combination of multiple data collection approaches.

Games can be used for both behavioural change and entertainment, and GBL can contain informative messages for promoting health-related behavioural change (Baranowski, Buday, Thompson, \& Baranowski, 2008). In their study, Baranowski et al. (2008) reviewed 25 video game articles related to promoting health-related behavioural change which included sex education messages for adolescents. They revealed that most of the reviewed articles demonstrated positive impacts on health-related behaviour change through game playing. Games can lead to moral and attitudinal change. Further research is needed to promote sex-related behavioural change through GBL in various socio-cultural contexts globally, particularly among young people.

In the same vein, the assessment by DeSmet A et al. (2014) of the efficacy of GBL in modifying sexual health-related behaviour using both systematic literature review and a meta-analysis found that since digital games are confidential in nature, they may encourage learners to discuss sexual topics regarded as confidential in some cultural backgrounds. Literature was obtained from various health-related databases dating from before July 2013. Seven GBL health-related articles were identified and included in the study. The studies showed significant sexual behavioural change through GBL. However, it was reported that these GBL studies did not employ many game features.

Finally, a study conducted in Hong Kong by Chu et al. (2015) developed a game application known as "Making Smart Choices" that addressed challenges encountered by adolescents in seeking access to sexual health education. Popular networking platforms such as Facebook and other web-based services, and smart devices such as iPads and smart phones are used to play the games. A total of 1,176 adolescents between 12-16 years old participated in playing the game. Qualitative and quantitative data were collected to evaluate the effectiveness of the intervention. They found that the students' knowledge of sexual health improved after playing the game. The game was described as interesting, interactive, informative, and real-to-life. It produced behavioural and attitudinal changes related to sex and relationships in school adolescents. This made GBL intervention appear promising for teaching adolescent sexual health education in Hong Kong.

\section{The Role of Gamification in Adolescent Sexual Health Education}

In the sexual health education context, gamification has also been used for both teaching and learning. For example, previous scholars (Arnab \& Clarke, 2015) have employed game mechanics such as scoring systems, to maximize engagement while investigating pressure and coercion in adolescent relationships. According to Shawaqfeh (2015), game elements are very important in improving knowledge gain and comprehension, as well as in increasing confidence levels among learners. Although, Shawaqfeh's study is not related to adolescent sexual health education, it is related to health education in general, as it focuses on pharmaceutical education.

Schoech et al. (2013) applied game mechanics to the evaluation of behavioural changes in regard to sexual and 
relationship violence control among adolescents. They used game elements such as challenges, a point system, bonuses, penalties, awards such as virtual money, feedback and scoring. The intention was to encourage, motivate, and engage students during learning. Furthermore, game elements enhanced self-disclosure, co-learning, and the comprehensive delivery of the lesson to the intended students. Thus, game elements are important in teaching and learning, and in facilitating adolescents to gain the information they need to curb irresponsible sexual behaviours that prohibit them from reaching their future goals.

\section{Conclusion and Way Forward}

The above-reviewed literature indicates that sexual health education has been conducted differently from country to country due to the different socio-cultural backgrounds of younger school students. Studies on GBL and gamification have been carried out primarily in developed countries, outside of Africa. Thus, they lacked experience in a local African context, as there is no literature from the continent which identifies this topic. In spite of the large amount of school curricula adopted in Tanzania to teach sexual health literacy to adolescents, the majority of these curricula vary in terms of quality, completeness, coverage of content, scope and consistency, making them questionable and giving rise to the need for the present study.

This study is also in response to the call by Mkumbo (2008) for new research into the effectiveness of instructional methods used by teachers in promoting sexual health education to adolescents in Tanzania. Additionally, although sexual education has been part of the curriculum for a couple of decades in most schools in Tanzania, irresponsible adolescent sexual behaviour has been increasing sharply. This is because traditional instructional methods, which are more widely used to teach sexual health education nationally than any other method, seem ineffective. Our hope is to increase Tanzanian adolescents' knowledge of sexual and reproductive health using empirically proven and innovative teaching tools, namely game-based learning and gamification, and suggest appropriate strategies for evaluating learning outcomes. Through this review, we have gained an understanding of the study area, and have thus sought to comprehend what are the foundations of the field and what should be the focus of this study, which is to design innovative GBL and Gamification with emphasis on African settings and on Tanzania in particular.

\section{Author's Contribution}

All authors participated equally to the development of this manuscript. All authors read and approved the final manuscript.

\section{Conflict of Interest}

The authors declare that there are no conflicts of interest present in this study.

\section{Funding}

This research received no specific grant from funding agencies in the public, commercial, or not-for-profit sectors.

\section{References}

Admiraal, W., Huizenga, J., Akkerman, S., \& Dam, G. Ten. (2011). The concept of flow in collaborative game-based learning. Computers in Human Behavior, 27(3), 1185-1194. https://doi.org/10.1016/j.chb.2010.12.013

Ahmed, N., Flisher, A. J., Mathews, C., Mukoma, W., \& Jansen, S. (2009). HIV education in South African schools: the dilemma and conflicts of educators. Scandinavian Journal of Public Health, 37 Suppl 2(August 2008), 48-54. https://doi.org/10.1177/1403494808097190

Akkus, R., Gunel, M., \& Hand, B. (2007). Comparing an inquiry-based approach known as the science writing heuristic to traditional science teaching practices: Are there differences? International Journal of Science Education, 29(14), 1745-1765. https://doi.org/10.1080/09500690601075629

Arnab, S., Brown, K., Clarke, S., Dunwell, I., Lim, T., Suttie, N., ... De Freitas, S. (2013). The development approach of a pedagogically-driven serious game to support Relationship and Sex Education (RSE) within a classroom setting. Computers and Education, 69, 15-30. https://doi.org/10.1016/j.compedu.2013.06.013

Arnab, S., \& Clarke, S. (2015). Towards a trans-disciplinary methodology for a game-based intervention development process. British Journal of Educational Technology. https://doi.org/10.1111/bjet.12377

AVERT. (2016). HIV AND AIDS IN TANZANIA: Global information and advice on HIV \& AIDS. Retrieved September 15, 2016, from http://www.avert.org/professionals/hiv-around-world/sub-saharanafrica/tanzania\#footnote16_i9h45mp 
Baranowski, T., Buday, R., Thompson, D. I., \& Baranowski, J. (2008). Playing for Real. Video Games and Stories for Health-Related Behavior Change. American Journal of Preventive Medicine. https://doi.org/10.1016/j.amepre.2007.09.027

Behnke, K. A. (2015). Gamification in Introductory Computer Science. PhD Thesis. University of Colorado Boulder.

Bilinga, M. J. (2016). Sexuality Education for Prevention of Pregnancy and HIV Infections: How do Tanzanian Primary Teachers Deliver it ? International Journal of Sciences: Basic and Applied Research, 26(3), 66-87.

Bilinga, M., \& Mabula, N. (2014). Teaching Sexuality Education in Primary Schools in Tanzania: Challenges and Implications. Journal of Education and Practice, 5(27), 21-31. Retrieved from http://www.iste.org/journals/

Blunt, R. (2006). A causal-comparative exploration of the relationship between Game-Based Learning and academic achievement: Teaching management with video games. PhD Thesis. Walden University.

Bowen, E., Walker, K., Mawer, M., Holdsworth, E., Sorbring, E., Helsing, B., ... Jans, S. (2014). "It's like you're actually playing as yourself": Development and preliminary evaluation of "Green Acres High", a serious game-based primary intervention to combat adolescent dating violence. Psychosocial Intervention, 23(1), 43-55. https://doi.org/10.5093/in2014a5

Buston, K., Wight, D., Hart, G., \& Scott, S. (2002). Implementation of a teacher-delivered sex education programme: obstacles and facilitating factors. Health Education Research, 17(1), 59-72. https://doi.org/10.1093/her/17.1.59

Che, F. S. (2005). A study of the implementation of sex education in Hong Kong secondary schools. Sex Education, 5(3), 281-294. https://doi.org/10.1080/14681810500171458

Chu, S. K. W., Kwan, A. C. M., Reynolds, R., Mellecker, R. R., Tam, F., Lee, G., ... Leung, C. Y. (2015). Promoting Sex Education Among Teenagers Through an Interactive Game: Reasons for Success and Implications. Games for Health Journal, 4(3), 168-174. https://doi.org/10.1089/g4h.2014.0059

Cicchino, M. (2013). Using Game-Based Learning to foster critical thinking in student discourse. PhD Thesis. The State University of New Jersey.

DeSmet A, Van Ryckenghem D, Compernolle S, Baranowski, T., Thompson D, Crombez G, ... De Bourdeaudhuij I. (2014). A Meta-Analysis of Serious Digital Games for Healthy Lifestyle Promotion. Preventive Medicine, 2(2), 95-107. https://doi.org/10.14440/jbm.2015.54.A

Dicheva, D., Dichev, C., Agre, G., \& Angelova, G. (2015). Gamification in Education: A Systematic Mapping Study. Journal of Educational Technology \& Society, 18(3), 75-88.

Eggers, S. M., Aarø, L. E., Bos, A. E. R., Mathews, C., Kaaya, S. F., Onya, H., \& de Vries, H. (2016). Sociocognitive Predictors of Condom Use and Intentions Among Adolescents in Three Sub-Saharan Sites. Archives of Sexual Behavior, 45(2), 353-365. https://doi.org/10.1007/s10508-015-0525-1

Filsecker, M., \& Hickey, D. T. (2014). A multilevel analysis of the effects of external rewards on elementary students' motivation, engagement and learning in an educational game. Computers \& Education, 75, 136-148. https://doi.org/10.1016/j.compedu.2014.02.008

Garcia, I., Barberà, E., Gros, B., Escofet, A., Fuertes, M., Noguera, I., ... Marimón, M. (2014). Analysing and supporting the process of co-designing inquiry-based and technology-enhanced learning scenarios in higher education. In S. Bayne, C. Jones, M. de Laat, T. Ryberg, \& C. Sinclair (Eds.), Proceedings of the 9th International Conference on Networked Learning 2014 (pp. 493-501). Edinburgh: University of Edinburgh. Retrieved from http:/www.networkedlearningconference.org.uk/abstracts/pdf/garcia.pdf

Hanus, M. D., \& Fox, J. (2015). Assessing the effects of gamification in the classroom: A longitudinal study on intrinsic motivation, social comparison, satisfaction, effort, and academic performance. Computers and Education, 80, 152-161. https://doi.org/10.1016/j.compedu.2014.08.019

Harrold, D. J. (2015). Game on: A qualitative case study on the effects of gamified curriculum design on student motivational learning habits. PhD Thesis. Robert Morris University. Retrieved from http://search.proquest.com.ezplib.ukm.my/docview/1673159776?accountid=27931

Hew, K. F., Huang, B., Chu, K. W. S., \& Chiu, D. K. W. (2016). Engaging Asian students through game mechanics: Findings from two experiment studies. Computers and Education, 92-93, 221-236. https://doi.org/10.1016/j.compedu.2015.10.010 
Hong Kong Department of Health. (2014). Survey of Life Skills- Based Education on HIV/AIDS at Junior Level of Secondary Schools in Hong Kong. Hong Kong.

Hsu, J. H.-L. (2010). Does education encourage the ABCs: Abstain, Be faithful and Condomize? A study of determinants of HIV/AIDS infections among Cape Town youth from 2002-2006. Masters Thesis. Georgetown University.

Jack, L. M. (2015). An analysis of the implementation and the effect of jigsaw and think-pair-share cooperative learning strategies on ninth grade students' achievement in Algebra I. Southern University and A \& M College.

Jimenez-gomez, D. (2015). Cognitive foundation of strategic behaviour: From games to revolutions. PhD Thesis. Massachusetts Institute of Technology.

Kapp, K. M. (2012). The Gamification of Learning and Instruction: Game-Based Methods and Strategies for Training and Education. San Francisco: Pfeiffer. https://doi.org/10.1145/2207270.2211316

Kapp, K. M., Blair, L., \& Mesch, R. (2013). The gamification of learning and instruction fieldbook: Theory into practice. New York, NY: John Wiley \& Sons.

Kirby, D. (2002). The impact of schools and school programs upon adolescent sexual behavior. Journal of Sex Research, 39(1), 27-33. https://doi.org/10.1080/00224490209552116

Klepp, K., Flisher, A. J., \& Kaaya, S. F. (2008). Promoting Adolescent Sexual and Reproductive Health in East and Southern Africa. (K.-I. Klepp, A. J. Flisher, \& S. F. Kaaya, Eds.). Cape Town: HSRC Press.

Kohler, P. K., Manhart, L. E., \& Lafferty, W. E. (2008). Abstinence-Only and Comprehensive Sex Education and the Initiation of Sexual Activity and Teen Pregnancy. Journal of Adolescent Health, 42(4), 344-351. https://doi.org/10.1016/j.jadohealth.2007.08.026

Landers, R. N., \& Callan, R. C. (2011). Casual social games as serious games: the psychology of gamification in undergraduate education and employee training. In M. Ma, A. Oikonomou, \& L. C. Jain (Eds.), Serious Games and Edutainment Applications (pp. 399-423). London: Springer-Verlag London Limited. https://doi.org/10.1007/978-1-4471-2161-9

Liu, C., \& Long, F. (2014). The Discussion of Traditional Teaching and Multimedia Teaching Approach in College English Teaching. In International Conference on Management, Education and Social Science. Beijing: Atlantis Press.

Makoye, K. (2015). Tanzania rolls out sex education to curb teenage pregnancies. Retrieved June 13, 2016, from http://af.reuters.com/article/topNews/idAFKCN0ST1S420151104?sp=true

Mathews, C., Aarø, L. E., Grimsrud, A., Flisher, A. J., Kaaya, S., Onya, H., ... Klepp, K. I. (2012). Effects of the SATZ teacher-led school HIV prevention programmes on adolescent sexual behaviour: Cluster randomised controlled trials in three sub-Saharan African sites. International Health, 4(2), 111-122. https://doi.org/10.1016/j.inhe.2012.02.001

McGonigal, J. (2011). Reality is broken: Why games make us better and how they can change the world. New York (Vol. 22). https://doi.org/10.1075/ni.10.1.03bro

Mellanby, A. R., Newcombe, R. G., Rees, J., \& Tripp, J. H. (2001). A comparative study of peer-led and adult-led school sex education. Health Education Research, 16(4), 481-492. https://doi.org/10.1093/her/16.4.481

Mkumbo, K. A. (2009). Content analysis of the status and place of sexuality education in the national school policy and curriculum in Tanzania. Educational Research and Review, 4(12), 616-625.

Mkumbo, K., Schaalma, H., Kaaya, S., Leerlooijer, J., Mbwambo, J., \& Kilonzo, G. (2009). The application of Intervention Mapping in developing and implementing school-based sexuality and HIV/AIDS education in a developing country context: the case of Tanzania. Scandinavian Journal of Public Health, 37(2), 28-36. https://doi.org/10.1177/1403494808091345

Mlyakado, B. P. (2013a). Attitudes and Views of Teachers Towards Students' Sexual Relationships in Secondary Schools in Tanzania, 4(1), 232-241.

Mlyakado, B. P. (2013b). Schoolgirls' Knowledge of, and Efforts against Risky Sexual Activity: The Needs for Sex Education in Schools. International Journal of Education, 5(1), 69-80. https://doi.org/10.5296/ije.v5i1.2825

MoEVT. (2014). OET 302: HIV and Sexuality Education Curriculum-based and Comprehensive Approach. Dar Es 
Salaam: The Ministry of Education and Vocational Training, Teacher Educators Programme and The Open University of Tanzania.

Mueller, T. E., Gavin, L. E., \& Kulkarni, A. (2008). The Association Between Sex Education and Youth's Engagement in Sexual Intercourse, Age at First Intercourse, and Birth Control Use at First Sex. Journal of Adolescent Health, 42(1), 89-96. https://doi.org/10.1016/j.jadohealth.2007.08.002

Naidoo, M. (2006). An evaluation of the sexuality education programme being implemented in South African schools. PhD Thesis. University of Zululand. Retrieved from http://196.21.83.35/handle/10530/246

Okazaki, S. (2002). Influences of culture on Asian Americans' sexuality. Journal of Sex Research, 39(1), 34-41. https://doi.org/10.1080/00224490209552117

Okonofua, F. (2014). Confronting the challenge of reproductive health in Africa: a textbook for students and development practitioners. (F. E. Okonofua, Ed.). Florida: Women's Health and Action Resource Centre. Retrieved from https://mitpress.mit.edu/sites/default/files/titles/free_download/9780262513623_Confronting_the_Challeng es.pdf

Perry, D. (2016). An Analysis of Game-Based Learning for the Design of Digital Science Games. PhD Thesis. University of Washington.

Peter, H. (2013). Assessment of knowldge on reproductive health among adolescents attending secondary schools in Moshi Municipality of Kilimanjaro, Tanzania. Masters Thesis. The Open University of Tanzania.

Ponzetti, J. J. (2016). Evidence-based Approaches to Sexuality Education: A Global Perspective. (J. J. Ponzetti, Ed.). New York: Routledge: Taylor \& Francis Group.

Population Council. (2012). Sexuality education: a ten-country review of school curricula in East and Southern Africa. (D.-Z. Pedra, Ed.). New York: UNESCO and UNFPA. https://doi.org/10.4135/9781412963916.n341

Schoech, D., Boyas, J. F., Black, B. M., Elias-Lambert, N., Boyas F., J., \& Black M., B. (2013). Gamification for Behavior Change: Lessons from Developing a Social, Multiuser, Web-Tablet Based Prevention Game for Youths. Journal of Technology in Human Services, 31(April 2015), 197-217. https://doi.org/10.1080/15228835.2013.812512

Schwerdt, G., \& Wuppermann, A. C. (2011). Is traditional teaching really all that bad? A within-student between-subject approach. Economics of Education Review, 30(2), 365-379. https://doi.org/10.1016/j.econedurev.2010.11.005

Shaw, D. (2009). Access to sexual and reproductive health for young people: Bridging the disconnect between rights and reality. International Journal of Gynecology and Obstetrics, 106(2), 132-136. https://doi.org/10.1016/j.ijgo.2009.03.025

Shawaqfeh, M. S. (2015). Pharmaceutical Care \& Health Systems Gamification as a Learning Method in Pharmacy Education. J Pharma Care Health Sys, S2-4. https://doi.org/10.4172/jpchs.S2-004

Shegesha, M. B. (2015). Tutors 'Experiences of Sex and Relationships Education in Tanzania. Masters Thesis. Hedmark University College. Retrieved from https://brage.bibsys.no/xmlui/bitstream/id/391406/Shegesha.pdf

Shemsanga, E. N. (2013). The Culture of "Silent Sexuality" Amongst The Shambala of Tanzania: Towards an Intercultural Approach in the Pastoral Ministry. PhD Thesis. University of Stellenbosch.

Simõesa, J., Redondob, R. D., \& Vilasb, A. F. (2013). A social gamification framework for a K-6 learning platform. Computers in Human Behavior, 29(2), 345-353. https://doi.org/doi:10.1016/j.chb.2012.06.007

Smith, K. A., \& Harrison, A. (2013). Teachers' attitudes towards adolescent sexuality and life skills education in rural South Africa. Sex Education, 13(1), 68-81. https://doi.org/10.1080/14681811.2012.677206

Sommer, M., Likindikoki, S., \& Kaaya, S. (2015). ???Bend a Fish When the Fish Is Not Yet Dry???: Adolescent Boys??? Perceptions of Sexual Risk in Tanzania. Archives of Sexual Behavior, 44(3), 583-595. https://doi.org/10.1007/s10508-014-0406-z

Speizer, I. S., Magnani, R. J., \& Colvin, M. A. (2003). The effectiveness of adolescent reproductive health interventions in developing countries: a review of the evidence. Journal of Adolescent Health, 33(5), 324-348.

The Commission on Population and Development. (2012). Resolution 2012/1 Adolescents and Youth: Forty-Fifth 
Session, Draft Resolution. Retrieved from http://www.un.org/esa/population/cpd/cpd2012/Agenda item 8/Decisions and resolution/Resolution 2012_1_Adolescents and Youth.pdf

The United Republic of Tanzania. (2013). Tanzania Third National Multi-Sectoral Strategic Framework for HIV AND AIDS (2013/14 - 2017/18. Dar Es Salaam.

Tiendrebéogo, G., Meijer, S., \& Engleberg, G. (2003). Life Skills and HIV Education Curricula in Africa: Methods and Evaluations. Washington, D.C.

Ubora wa Afya kwa Familia Duniani. (2001). Adolescent Sexual and Reproductive Health: Report on an Assessment and Review of Training Materials. Dar Es Salaam.

UNAIDS. (2016). Global AIDS Update 2016: Enormous gains, persistent challenges. Geneva. Retrieved from http://www.who.int/hiv/pub/arv/global-AIDS-update-2016_en.pdf?ua=1

UNESCO. (2013). Young People Today. Time to Act now: Why adolescents and young people need comprehensive sexuality education and sexual and reproductive health services in Eastern and Southern Africa. Paris. Retrieved from www.unesco.org/aids

Walcott, C. M., Meyers, A. B., \& Landau, S. (2008). Adolescent sexual risk behaviors and school-based sexually transmitted infection/HIV prevention. Psychology in the Schools. https://doi.org/10.1002/pits.20277

WHO. (2016). HIV/AIDS: Fact sheet. Retrieved September 15, 2016, from http://www.who.int/mediacentre/factsheets/fs360/en/

Wight, D., \& Fullerton, D. (2012). A review of interventions with parents to promote the sexual health of their children (Structured abstract). Journal of Adolescent Health, Jun 2012(4), 4-27. Retrieved from http:/onlinelibrary.wiley.com/o/cochrane/cldare/articles/DARE-12012028388/frame.html

Wight, D., Plummer, M., \& Ross, D. (2012). The need to promote behaviour change at the cultural level: one factor explaining the limited impact of the MEMA kwa Vijana adolescent sexual health intervention in rural Tanzania. A process evaluation. BMC Public Health, 12(1), 788. https://doi.org/10.1186/1471-2458-12-788

$\mathrm{Xu}, \mathrm{Y}$. (2012). Language technologies in speech-anabled Language learning Games: From reading to dialogue. (PhD Thesis. Massachusetts Institute of Technology).

\section{Copyrights}

Copyright for this article is retained by the author(s), with first publication rights granted to the journal.

This is an open-access article distributed under the terms and conditions of the Creative Commons Attribution license (http://creativecommons.org/licenses/by/4.0/). 